From the Department of Child Health, Institute of Pathology and Department of Surgery, Medical School, University of Indonesia, Jakarta

\title{
Congenital Defect in the Musculature of the Stomach with Spontaneous Rupture in a Newborn Infant. (Case Report)
}

\section{by \\ ZAIMI ZET, SADIKIN DARMAWAN and DARMAWAN KARTONO}

Beyond the neonatal age group congenital defect in the musculature of the stomach with spontaneous rupture is a rare condition. The clinical findings are dyspnoea, abdominal distension with or without hematemesis/melaena '(Herbut, 1943).

In most of the cases symptoms are present on the 3rd-5th diay after birth.

$\mathrm{X}$-photos of the abdiomen show free air in the abdominal cavity. Brody in 1940, followed by Herbut in 1943 , reported the first case of congenital defects of the gastric musculature. Thereafter until the publication of Amedo et al. (1960) only 13 other cases were described with histological confirmation of a defect in the musculature of the stomach. The diagnosis of perforation is made by the presence of free air in the abdo- minal cavity on X-photos of the abdomen.

In this communication a case of spontaneous gastric perforation due to congenital defect in the gastric musculature, proven by histological examination, will be reported.

\section{Case report}

A male infant was born at $8.10 \mathrm{p}$. m. on November 2, 1971, to a 29year-old Indonesian woman by Cesarean Section due to cervical dystocia caused by a itumor which blocked the passage of labour associated with intrapartum infection and anemia. This was the 4th pregnancy of the mother with 3 children. The infant's condition at birth was good (Apgar score 9 after 1 minute and 10 after 5 minuites). No resuscitaltion or respiratory stimulant was needed, the cry was loud and lasting. The birth 
length was $46 \mathrm{~cm}$ and the birth weight $2.940 \mathrm{gm}$. The infant was taken to the nursery, where physical examination did not reveal any abnormality. The infant was handled carefully, no unnecessary manipulation was allowed. Formula feeding was started 6 hours after the fasting period.

On November 4 , at 5.30 a.m., the abdomen became distended (meteoristic). The child was dyspnoeic, defecation was normal and there was no vomiting. Rontgenograms of the abdomen were taken while oxygen was given. Anal and gastric tube were instituted.

After 2 hours the abdomen became more distended, the child was dyspnoeic and cyanotic.

Yellowish fluid came out from his nose and mouth. Liver dullness disappeared. Röntgenograms showed the presence of free air in the peritoneal cavity (Fig. 1 and 2).

The patient was referred to the Surgical Department and the diagnosis of neonatal gastric perforation was made. Therapy with Penicillin and Kanamycine was started and intravenous fluid drip was instituted.

The abdomen was explored. There was air indeed escaping from the abdominal cavity and approximately $100 \mathrm{ml}$ yellowish fluid were removed. Peritonitis and total rupture along the greater curvature were seen. Hiscological examination results in the finding of muscular deficiency (Fig. 3 and 4).

On November 5, 1971 at 4.15 a.m. the infant became dyspnoeic and cyanotic. Oxygen was given again and artificial respiration was performed, however in vain and the child died.

\section{Discussion}

Awareness among pediatricians and obstetricians of the possibility of perforation of the stomach is a prime prerequisite for its diagnosis.

Any newborn infant, particularly a premature, who seems to do well for the first 2 or 3 days and then develops abdominal distension should be suspected for the possibility of gastric rupture and rontgenograms of the abdomen should be made.

The diagnosis of gastric perforation is based mainly on the demonstration of pneumoperitoneum, although its presence is by no means pathognomonic. Rontgenograms in the upright and lateral decubitus position should be taken routinely and will in most cases establish the diagnosis of pneumoperitoneum, whereas if only a supine film is obtained, the diagnosis may be missed. The amount of free air depends upon the size and location of the perforation as well as on the time elapsed before rontgenogråms are obtained.

The demonstration of free fluid and signs of peritoneal irritation are important findings in confirming the diagnosis. 
Contrast studies are not necessary. In the preparation for surgery considerable efforts should be expended in maintaining the infant's normal body temperature.

Intravenous fluid therapy was very important to correct dehydration if present before, during and after surgery. As many of these infants have peritonitis at the time of surgery, the administration of antibiotics and the institution of nasogastric suction should be started when presumptive diagnosis is made.

In this case endotracheal anesthesia was performed. The child was awake at the end of the operation and was returned to the ward in an Isolette for the maintainance of body temperature and humidity. Meyer (1957) correctly reported that the majority of spontaneous rupture occurred along the greater curvature, also in this case we found the rupture along the greater curvature of the stomach. Postoperatively, fluid therapy and anitibiotics were given. Unfortunately the infant died a few hours after surgery, may be due to peritonitis.

\section{Summary}

A rare case of spontaneous gastric perforation due to congenital defect of the masculature in an Indonesian newborn has been reported.

Abdominal distension, absence of bowel sound, and dyspnea were the major clinical signs.

\section{Acknowledgement}

The authors are very grateful to Professor Sutedjo for his encouragement to publish this case and for his help in preparing the manuscript.

\section{REFERENCES}

1. AMEDO, J.H., ASHMORE, H.W., and APONTE, G.E.,: Neonatal gastric perforation caused by congenital defects of the musculature. Surgery $47: 1010$ (1960).

2. BRODY, H.: Ruptured diverticulum of the stomach in a newborn with a congenital membrane occluding the duodenum. Arch. Path. $29: 125$ (1940).

3. HERBUT, P.A.: Congenital defect in the musculature of the stomach with rupture in the newborn infant. Arch. Path. 36 : 91 (1943).
4. Mc. CORMICK, W.F.: Rupture of the stomach in children; review of the literature and a report of seven cases. Arch. Path. 67 : 416 |(1959).

5. MEYER, J.L., II: Congenital Defect in the Musculature of the Stomach Resulting in Spontaneous Gastric perforation in the Neonatal Period. J. Pediatr. $51: 416$ (1957).

6. REAMS, G.B., DUNAWAY, J.B. and WALLS, W.L.: Neonatal gastric perforation with survival. Pediatrics 31 : 97 (1963). 